\title{
A Man's world? Comparing the structural positions of men and women in an organized criminal network
}

\author{
Tomáš Diviák ${ }^{1,2,3}$ (1) James A. Coutinho ${ }^{4}$ Alex D. Stivala ${ }^{4,5}$
}

Published online: 5 August 2020

(C) The Author(s) 2020

\begin{abstract}
The crime gender gap is the difference between the levels of participation of men and women in crime, with men responsible for more crime than women. Recent evidence suggests that the crime gender gap is closing, both in crime in general and in organized crime. However, organized crime differs from other forms of criminal activity in that it entails an organizational structure of cooperation among offenders. Assessing whether the gender gap in organized crime is narrowing is not only about the overall levels of involvement of women, but about their roles and positions within the organized criminal structure, because the involvement of women does not mean that they are in influential positions, or that they have power or access to resources important for the commission of organized crime. This paper uses a social network approach to systematically compare the structural positions of men and women in an organized criminal network. We use a dataset collected by Canadian Law Enforcement consisting of 1390 individuals known or suspected to be involved in organized crime, 185 of whom are women. Our analysis provides evidence for an ongoing gender gap in organized crime, with women occupying structural positions that are generally associated with a lack of power. Overall, women are less present in the network, tend to collaborate with other women rather than with men, and are more often in the disadvantageous position of being connected by male intermediaries. Implications for theory and law enforcement practice are discussed.
\end{abstract}

Keywords Social network analysis · Autologistic actor attribute models · Organized crime · Criminal networks · Gender

Tomáš Diviák

t.diviak@ rug.nl

Extended author information available on the last page of the article 


\section{Introduction}

The crime gender gap is the difference between the participation of men and women in crime, with men responsible for more crime than women. The crime gender gap is one of the most persistent and well-documented patterns in social sciences [1-3]. There are numerous explanations for the underlying processes behind this pattern, such as different structure of opportunities for males and females, differential influence of deviant peers, different cognitive or emotional predispositions, and even biologicallyoriented explanations linking differences in crime to hormonal differences [1, 4]. Despite the persistence of this pattern and numerous candidate explanations for it, the gap between men's and women's involvement in petty crime has been narrowing in recent years (cf. [1]). There is evidence for the gender gap in organized crime as well [5-7], leading to the question of whether the gender gap is narrowing in this domain as well.

The gap between men's and women's participation in, and outcomes from, legal economic activity has narrowed in recent decades. This raises the question of whether similar trends are present in the illegal economy. The question whether the gender gap is narrowing in organized crime is an open one with some evidence based on official statistics [5] and from case studies [8] suggesting that the gap might be narrowing, whereas other research from studies on white collar crime and criminal enterprises points in the opposite direction $[9,10]$. Organized crime is fundamentally different from other forms of crime in that it entails an organizational structure of cooperation among offenders (cf. [11, 12]). Seen from this perspective, the case of organized crime is then not only about the sheer involvement of women, but predominantly about the roles they play and positions within its structure, because the involvement of even a large number of women does not mean that they are in influential positions, or that they have power or access to resources important for the commission of organized crime. Indeed, we cannot fully understand economic, social or organizational power without theorizing and measuring power in structural terms [13]. We aim to contribute to this debate on the crime gender gap by focusing on comparison between structural positions of men and women in organized crime. Some studies explore the roles women play within organized crime groups, and the structural positions they hold [5]. These studies point out specific activities and roles of women, but in order to be able to assess gender differences, it is necessary to not only point out the positions and roles of women, but also systematically compare them to men. The social network perspective [14-16] provides a framework for such a comparison, as it allows us to view organized crime as a network of interactions and relations among offenders and to empirically assess individual structural positions of males and females within the network [17, 18]. Moreover, statistical models for social networks go beyond description, allowing us to draw inferences about systematic differences between the roles that men and women play in organized crime.

In this study, we examine the similarities and differences between network positions of men and women in organized crime networks. We review current theory and previous research findings on gender and organized crime and on positions of women in networks in general, from which we derive hypotheses on structural differences between men and women $[19,20]$. We apply statistical models specifically designed for social network data called auto-logistic actor attribute models (ALAAM; [21, 22]), 
to a large anonymized dataset on organized crime originating from law enforcement investigations in the Canadian Province of Alberta. The data consists of 1390 individuals known or suspected to be involved in organized crime over a two-year period from 2014. Network ties in the data represent criminal collaboration and personal relationships between individuals. The data contain a substantial proportion of women, allowing us to compare the structural positions of men and women. The results of our analysis show that women are less present in the network, tend to be connected to other women, and that women are more often in the disadvantageous position of being connected by male intermediaries. Importantly, we find fewer marked structural differences between men's and women's networks than have been suggested by previous research, but we nonetheless find significant evidence for an ongoing gender gap in organized crime.

\section{Organized crime and networks}

There have been numerous theoretical attempts to conceptualize organized crime and explain how it is in fact organized. One of the first theoretical descriptions was of organized crime as a hierarchy akin to firms and bureaucracies [23]. More economically-inclined researchers compared organized crime to markets, and still others drew upon anthropologically inspired studies on kinship and ethnic communities [23]. However, these theories assumed structural properties of organized crime (such as hierarchy) instead of empirically examining the structure of actual organized crime systems. In contrast, a social network approach requires no such a priori assumptions about the structure of organized crime as it relies on the "least common denominator" [18] of all types of organized crime - interactions and relations among a group of actors. We approach organized crime as such a structure among collaborating actors [24] which allows us to systematically compare the structural positions of men and women.

Social network research on organized crime has focused predominantly on structural properties of criminal networks and on central actors within them, producing insightful findings about the way criminals use networks to organize and about the network characteristics of key players [25-27]. While there are pioneering studies investigating individual attributes and qualities of actors as antecedents or outcomes of network structures (e.g., skills or formal hierarchy; $[28,29])$, gender as an attribute has been largely neglected in the network research on organized crime. Individuals initiate or end interpersonal ties, and thus acquire network positions, based on the opportunities and constraints given by their capacities and characteristics [30]. Gender can be seen as a special case of these individual characteristics in that the effect of gender on social networks is thought to operate partly through systematic social-structural constraints and opportunities that apply differently to men and to women [9, 31]. Since organized crime has been considered male-dominated [5-7], it may be more difficult for a woman to become involved in the network (for example, potential male accomplices may be unwilling to work with them). Alternatively, women's gender may create opportunities for them (for example, they may not raise the same level of suspicion as men do. We seek to advance the understanding of the interplay between gender and structural positions within organized crime networks. 


\section{Gender, network positions and organized crime}

Attempts to decrease inequalities between men and women in various spheres of social life have attracted the attention of many social scientists. Among them are network researchers who have studied the positions of women and men in legitimate networks in business, work-related life, immigration, the film industry and local elites [32-34]. The involvement of women in organized crime has also been studied $[6,35]$. From a network perspective, we can try to extrapolate the findings from legitimate networks to criminal networks. From an organized crime perspective, we can translate research findings into the language of networks. In this section, we derive our hypotheses based on previous research in both these areas. We note that the evidence from both fields is quite unclear and relatively scarce, and we therefore formulate our hypotheses based on the more dominant notions in the literature. Except where we state otherwise, our hypotheses relate to networks of criminal collaborative ties.

An intuitive way to compare men and women in organized crime would be to look at the percentage of women involved. Given the gender gap and general dominance of men in this domain, we would expect to see more men in these networks. This is supported by evidence from 1930's American mafia settings [7] as well as contemporary evidence - a study of Dutch organized crime found women constituting $11 \%$ of all offenders [36], in an Italian mafia study, women accounted for $2 \%$ of offenders [37], and in an Australian study, women represented $6 \%$ of 2172 offenders [38]. Overall, women are not present in a lot of observed covert networks and when they are present, there are usually fewer of them than men [39].

Even if higher proportions of women may be involved in crime than in the past, they may not necessarily be more powerful, influential or active in the network. Some conceptions view gender in terms of power relations between men and women [19]. Such a relational view of gender accords well with the network approach, where extensive research has shown that actors' positions in networks of interpersonal relationships relate to their power and influence [40]. In Smith's [7] study, there was a strong inequality between men and women in a variety of network positions in the Chicago pre-Prohibition era organized crime scene. This inequality sharply increased after the external shock of Prohibition. Power and influence in networks is often examined using the concept of centrality. Two conceptions of central actors that have shown to be relevant in a criminal context are those who are have more ties (are more active), and those who control important and/or numerous resource flows within the network and thus serve as a bridge between many other actors in the network [41]. Despite the fact that gender differences in networks may be disappearing in legitimate contexts which actively support gender equality [42], there are no such equality-promoting programmes in criminal environments and thus we would expect women to be less active and less influential in the network.

H1: There are fewer women than men in an organized crime network.

H2: Women have fewer ties in an organized crime network.

H3: Women are less likely to be positioned to control resource flows in an organized crime network. 
If we consider dyads - that is two actors connected by a tie - we can look at the differences between men and women through within-gender and cross-gender ties, i.e., whether women are connected in the network via other women or rather via men. The former tendency to associate with those who are similar on some salient attribute is known as homophily, and has been described as a persistent mechanism behind tie creation in a multitude of empirical settings $[43,44]$. The latter is the inverse tendency to seek partners with different attributes, known as heterophily. Again, Smith's [7] study on the Prohibition-era Chicago mafia found strong homophily among men, yet no such tendency among women. Even in more recent cases, mafia-type organizations are among the types of organized crime groups where women frequently participate only through their connections to men. This can be because they are introduced to mafia by their spouses or family members; or because they substitute for them in cases where the male is on the run, in prison or dead [45]. While both these cases would lead to heterophily, they have potentially different implications in terms of power. Women who fill in for their spouses may have the power and the ability to shape events, while women who connect via their spouses may not. Another type of organized crime where previous research found women to be involved via men (in other words, via heterophilous ties) is human/sex trafficking, where women are thought to be involved frequently because of their ability to embody traditionally gendered roles involving care and compassion, making them more persuasive with regard to interactions with victims [46]. Power-relevant heterophily effects are not exclusive to criminal networks - since male dominated social networks are reproduced by men forming ties to other men, if women do not want to be excluded from access to power or resources, they need to rely on heterophilous ties to men. This phenomenon has been documented in elite, business, and managerial networks $[42,47]$. Thus, heterophily for women may be more a matter of constrained opportunities than of preference [48].

H4: Women have more ties to men than to women in an organized crime network.

Related to the dyadic level of analysis is the question of pre-existing ties. These represent relations established between people prior to their direct involvement in criminal activity. Specifically, pre-existing ties may be kinship, friendship or shared affiliation to the same organizations or social settings [49]. Pre-existing ties are important because they may be a precondition for creating trust - a scarce yet crucial resource in criminal environments potentially compensating for the lack of institutions assuring the enforceability of commitments $[50,51]$. Thus, the presence of a pre-existing tie between two actors in a criminal network may facilitate their criminal cooperation. The effect of pre-existing ties is usually strong in criminal networks regardless of gender. The question is whether pre-existing ties work differentially for men and for women. There is some evidence from mafia-type groups suggesting that women become involved in these groups either as substituting for their incapacitated partners and family members or they are introduced by them into the group [52]. Due to constraints in access to organized criminal activities for women [6, 7, $10]$, the use of pre-existing ties may be a much stronger entry mechanism for women than it is for men.

H5: Women are connected more via pre-existing ties in an organized crime network. 
Additional complexity arises when we consider triadic configurations (subsets of three connected nodes) and their interplay with gender. Three nodes can be connected either partially via only two ties (resulting configuration called a two-path) or completely, forming a triangle. Two-paths are a network expression of brokerage roles or behaviours $[53,54]$. In two-paths, the intermediary actor with two ties is the broker who is in an advantageous position over the remaining two actors, as in order to reach each other, these two actors rely on the broker. This enables the broker to exploit his or her position, either by engaging in arbitrage and generating a profit, by controlling information flows, or by accessing diverse information and resources [44, 53]. Network brokerage is a common social mechanism observed in a variety of empirical settings. However, research suggests that brokerage may be even more important in the criminal domain, because it connects actors without creating redundant ties (unlike triangles), which would increase the risk of detection by increasing the number of observable relationships and interactions $[55,56]$. While in general, brokerage is regarded as a source of advantage for the brokers, it is also important in criminal networks as a mechanism for assuring secrecy. Regarding the role of women in organized crime, previous research indicates that brokerage was a niche role or behaviour which was sought out by women. For instance, so-called madams have been documented to hold positions of brokers in sex trafficking, though there was considerable variance among madams in terms of brokerage [57]. In the aforementioned Dutch study by Kleemans et al. [36], women were frequently found in brokerage positions too, though the notion of brokerage was conceptually wider - women brokered between countries (e. g., via marriage), contexts (e. g., via their knowledge of languages and ability to mediate) or groups (as women are supposed to raise less suspicion than men). However, systematic comparison on the difference between men and women in terms of brokerage is lacking.

H6: Women are more frequently in broker positions in an organized crime network.

Triangles are complete substructures which represent the opposite tendency to brokerage called (triadic) closure $[44,54]$. In triangles, everyone interacts with everyone else, creating conditions for the mutual monitoring of actions, the sharing of information, and thus the possibility that information is relatively homogenous among actors within the triad. Unlike brokerage, closure does not allow one actor the opportunity to exercise structurally-related power over the remaining two. Closure is frequently observed to be associated with social support, social control, trust and, and adhesion to social norms in variety of networks involving collaboration ties [58]. These mechanisms enable cooperation in legitimate settings [54]. These potential effects of closure appear to be important for criminal networks as well, since organized crime is a risky activity with no formal institutions to assure compliance or enforce commitments between actors $[30,51]$. In this context, closure is another means to establish trust in addition to preexisting ties. However, the question is whether this still holds when we consider the interaction between closure and gender. Some research on legitimate networks suggests that closure in networks may penalize women. Lutter [32] in his study of the US film industry found that women face a "closure penalty" - when they are embedded within closed structures, they have less career opportunities and their chance of failure is 
higher than in open structures. There is also some evidence from criminal networks supporting this idea - with increasing prevalence of triangles in the network, women became more marginal and less included within them [7]. Given that brokerage is supposed by many researchers to be the lever by which women acquire advantage within otherwise male dominated networks, it is logical that closure as the inverse mechanism is not beneficial for women.

H7: Women are less frequently involved in triangles in an organized crime network.

\section{Data}

We test our hypotheses using anonymized data consisting of 1390 individuals known or suspected to be involved in organized crime over a two-year period up to 2016. Of these 1390 individuals, 1205 are male and 185 are female. Organized crime is defined according to the Criminal Code of Canada as a group of three or more people whose main purpose or activity is the facilitation or commission of serious criminal offences that, if committed, would likely result in material benefits (including financial benefit) for at least one member of the group. Individuals represented in the data are known or suspected to be involved in a number of crime types, including property crimes, vehicle-related crimes, financial crimes, human trafficking, extortion/intimidation, weapons offences, and violent crime. However, the most common type of crime is drug trafficking. As Alberta lacks seaports that can be used for the importation of illicit drugs, organised criminal activity is heavily focused on the production of distribution of synthetic drugs. Indeed, methamphetamine possession rates are some of the highest in Canada [59].

Individuals were sampled from a larger data set of 3137 individuals. There are several types of network tie in the dataset, and for the purposes of analysis we aggregate these into two types: collaboration ties and pre-existing ties. Collaboration ties include ties between individuals who are known to law enforcement as being associated in criminal activities; who have been seen together by police surveillance or during police street checks; who are said to be associated by police sources; or who are reported as having criminal links in police case files. These collaboration ties can be seen as evidencing purposeful interactions, involving both direct (face-to-face) and indirect (e.g., phone calls, e-mails) communication. This dimension also includes collaboration on tasks or co-appearance at the same time in relevant places. Police use these relationships to confirm or infer the presence of criminal collaboration between individuals. Pre-existing ties are based on intelligence that suggests individuals are coworkers; have a romantic relationship or an ex-romantic relationship; a familial relationship; or a friendship relationship [49]. These tie types are evidence of relationships that likely predated any acts of criminal collaboration. Due to the risky nature of criminal collaboration, enduring or close relationships that engender trust and loyalty, or that make defection undesirable, are often observed to be pre-cursors to criminal activity. Romantic, familial and friendship relationships tend to be close, enduring and characterised by trust [14] and so reduce the risks associated with criminal collaboration. Workplace relationships also tend to be enduring and signal economic co- 
dependency, making defection among accomplices riskier and so facilitating cooperation. They might also indicate access to shared resources that can be used for the commission of crime. The relationship types, observed number of relationships in the data sample, and details of how they were derived by police and/or intelligence analysts are shown in Table 1. Note that relationship types are not mutually exclusive and more than one type can be present between two individuals. Individual cases were selected for analysis based on whether there was at least one network tie observed for that individual in the collaboration network (network degree $\geq 1$ ).

Table 1 Types of ties and their transformation

\begin{tabular}{|c|c|c|c|}
\hline Network & Tie type & Details of derivation & $\begin{array}{l}\text { Number of } \\
\text { observed } \\
\text { ties }\end{array}$ \\
\hline \multirow[t]{4}{*}{ Collaboration } & $\begin{array}{l}\text { Case file/criminal } \\
\text { links }\end{array}$ & $\begin{array}{l}\text { Individuals linked due to commission of criminal } \\
\text { activities; co-charged; co-accused; co-convicted. } \\
\text { Usually inferred by police/court occurrence reports } \\
\text { that set out those who have been charged. }\end{array}$ & 862 \\
\hline & Checkup/street check & $\begin{array}{l}\text { Individuals linked due to observation by police, leading } \\
\text { police to infer that they are criminal associates. } \\
\text { Observation could result from situations such as } \\
\text { individuals being observed together on a street } \\
\text { corner or individuals being observed together at an } \\
\text { Outlaw Motorcycle Gang clubhouse. Street checks } \\
\text { are brief reports that police make when documenting } \\
\text { things/people they observe or encounter. }\end{array}$ & 763 \\
\hline & Known associate & $\begin{array}{l}\text { 'Known associate' indicates that police have } \\
\text { information that confirms the association between } \\
\text { the people. The information could be from street } \\
\text { checks or other police reporting. }\end{array}$ & 1 \\
\hline & $\begin{array}{l}\text { Said to be associated } \\
\text { with (source } \\
\text { report) }\end{array}$ & $\begin{array}{l}\text { Information about a criminal association provided by a } \\
\text { person of interest and not by direct police } \\
\text { observation. }\end{array}$ & 468 \\
\hline \multirow[t]{4}{*}{ Pre-existing } & Co-worker & $\begin{array}{l}\text { This implies a legitimate business relationship of } \\
\text { co-worker. This might come from police observation } \\
\text { whereby they attend a business location and see the } \\
\text { individuals there and they claim to be employees or } \\
\text { co-workers or from documents about the individual } \\
\text { being employed in the same company. }\end{array}$ & 4 \\
\hline & Relationship & $\begin{array}{l}\text { Boyfriend/girlfriend/partner or } \\
\text { ex-boyfriend/girlfriend/partner. }\end{array}$ & 26 \\
\hline & Familial & Parents, children, siblings, spouses. & 63 \\
\hline & Friend & $\begin{array}{l}\text { A social relationship that does not involve any } \\
\text { suspected or actual crime, and is not a family or } \\
\text { business relationship, etc. Police might infer } \\
\text { friendship by direct observation (e.g. they are seen at } \\
\text { a bar together). }\end{array}$ & 21 \\
\hline
\end{tabular}




\section{Data limitations}

Data was collected by multiple police forces using a standardised form which prompts intelligence analysts for information regarding individuals under investigation, their attributes and their network ties; and then collated by a central police intelligence agency. Data come from multiple sources, including human intelligence (such as source reports, police surveillance), signals intelligence (such as the interception of communications), and open source intelligence (such as information freely available online). There are a number of limitations associated with intelligence data on covert activities, such as missingness, measurement error, anchoring bias (that is, focusing only on a partial set of individuals), or halo effect (e.g., when initially observed individuals get disproportionate coverage; [60]). It must also be acknowledged that while we have categorized ties into criminal collaborative and pre-existing based on criminal network theory, there is no information in the data that allows definite conclusions to be drawn regarding the temporal ordering of types of relationships between individuals. Despite these limitations it is important to acknowledge the expertise of the police personnel and intelligence analysts responsible for collecting and collating the data. Analysts use their expert judgement and apply knowledge and information not captured in the data to try to ensure that the data is an accurate representation of the criminally-relevant activities of individuals in population under surveillance. Further, intelligence data remains one of the best available means for understanding covert social networks $[25,26]$.

\section{Methods}

First, we calculate various descriptive measures. ${ }^{1}$ Density is the number of ties present in the network relative to the maximum number of possible ties in the network (that is the number of all pairs of nodes). The clustering coefficient is defined as a ratio of complete ("closed") triangles to all two-paths in the network - that is to all triads connected only by two ties. Both these measures take the range of $[0,1]$, where the closer to 1 the value is, the denser the network and the more closed triangles there are, both indicating higher cohesion. A path is a sequence of ties leading from one node to another, in which no tie nor node is repeated, and networks can be characterized by mean path length - shorter mean path length indicates the nodes in the network are closer to one another on average. A component is a maximally connected subgraph. In other words, all nodes in a component can reach one another by some path, and there is a no path between a node in the component and any node not in the component. The assortativity coefficient is Pearson's correlation coefficient between degrees of adjacent nodes [61] and it describes the tendency of actors of similar degree to be connected. Homophily on gender is measured by the assortativity coefficient on gender [62], where the value of +1 indicates perfect homophily whereas -1 indicates perfect heterophily.

\footnotetext{
${ }^{1}$ An up-to-date introductory overview for SNA terminology and descriptive methods is given, for example, by Borgatti et al. [14] or by Prell [15].
} 
Degree is the number of ties a node has - a higher number indicates greater centrality. The network can be characterized by mean degree of its constituent nodes. Betweenness centrality [41] measures the centrality of a focal node according to the number of shortest paths ("geodesics") between all pairs of actors in the network that the focal node is on. It therefore relies on the topology of the entire network rather than the local-structural configurations of nodes. It is thought to measure the amount of network 'flow' that passes through a given node and is usually interpreted as an indicator of individual influence.

Descriptive measures provide a good starting point for the comparison of men's and women's position with the network. However, they are insufficient for this task, as descriptive statistics do not account for randomness in network tie formation, nor statistical significance of the differences between men's and women's network positions. Hence, it is necessary to use a suitable statistical model which allows us to distinguish systematic outcomes from those brought about by random chance. Using statistical models for network data helps us to address one of the criticisms raised against the application of SNA to study criminal networks, namely its predominantly descriptive focus $[17,24]$. Statistical modelling of networks was specifically developed to overcome the shortcomings of descriptive SNA by permitting inferences about the underlying mechanisms responsible for the observed network data [63].

It is important to note that using standard statistical models such as regression analysis is not valid on network data for two reasons [63, 64]. First, network observations are not a random sample from a well-defined population, but rather a collection of actors and the interactions and relations among them observed for some specific reason (such as involvement in organized crime) with the aim of making inferences as to whether some postulated effects are systematically present or whether they could have arisen just by chance. Second, standard statistical models are built upon the cornerstone assumption that the observations are independent of one another. This assumption is violated in networks, as both nodes and ties are interdependent in the network. Therefore, we apply a model specifically designed to model interdependencies arising in network data.

Since our overall aim is to compare men and women in terms of their network positions, we use auto-logistic actor attribute models (ALAAM; [21, 22]). The dependent variable in the model is an actor attribute (in our case, gender ${ }^{2}$ ) explained by a combination of structural and individual variables. The structural predictors are represented by configurations, which are subgraphs expressing network substructures of theoretical interest. For instance, a configuration is a homophilous tie, i. e., a tie incident to actors who share an attribute (are both women for example), or a two-path in which a woman brokers between two other actors. The individual predictors are other attributes. The configurations we used to test our hypotheses are displayed with their graphical representation in Table 2. Although ALAAM has not yet been extensively used in the literature, there are applications testifying to its usefulness [66].

\footnotetext{
${ }^{2}$ Note that this use is unusual for ALAAM, which is usually used as a model of social influence, because gender does not change with the change of network structure (e.g., an actor does not become a woman by being embedded within structures occupied by many women). We use ALAAM as a network discriminant analysis [65] to distinguish structural differences between positions of men and women. Taking gender as a dependent variable is similar to approach taken by Edling et al. [42], although these authors used standard logistic regression.
} 
Table 2: ALAAM effects for interaction within the collaboration network

\begin{tabular}{|c|c|c|}
\hline Effect & Figure & Description \\
\hline Attribute-Density & & $\begin{array}{l}\text { The propensity of women to be involved in the } \\
\text { network }(\mathrm{H} 1) \text {. }\end{array}$ \\
\hline Activity & & $\begin{array}{l}\text { Propensity of women to be active or popular in } \\
\text { the network. Relates to } \mathrm{H} 2 \text {. }\end{array}$ \\
\hline Star2 & & $\begin{array}{l}\text { Propensity of women to create additional } \\
\text { ties. }(\mathrm{H} 2) \text {. }\end{array}$ \\
\hline Star3 & & $\begin{array}{l}\text { Propensity of women to create additional ties } \\
(\mathrm{H} 2) \text {. }\end{array}$ \\
\hline Contagion & & $\begin{array}{l}\text { Tendency of women to associate with } \\
\text { women(H4). }\end{array}$ \\
\hline $\mathrm{T} 1$ & & $\begin{array}{l}\text { Tendency of women to be involved in closed } \\
\text { structures (H7). }\end{array}$ \\
\hline $\mathrm{T} 2$ & & $\begin{array}{l}\text { Tendency of women to be involved in closed } \\
\text { structures with women (H7). }\end{array}$ \\
\hline T3 & & $\begin{array}{l}\text { Tendency of women to be involved in women- } \\
\text { only closed structures (H7). }\end{array}$ \\
\hline Setting-Homophily & & $\begin{array}{l}\text { Tendency of women to associate to other } \\
\text { women via pre-existing ties }(\mathrm{H} 4) \text {. }\end{array}$ \\
\hline 2-Path-Equivalence & & $\begin{array}{l}\text { Tendency of women to rely on brokers to be } \\
\text { connected }(\mathrm{H} 6) \text {. }\end{array}$ \\
\hline Partner-Activity & & $\begin{array}{l}\text { Tendency of women to rely on brokers to be } \\
\text { connected (H6). }\end{array}$ \\
\hline Partner-Resource & & $\begin{array}{l}\text { Tendency of women to rely on brokers to be } \\
\text { connected }(\mathrm{H} 6) \text {. }\end{array}$ \\
\hline $\begin{array}{l}\text { Betweenness } \\
\text { centrality }\end{array}$ & & $\begin{array}{l}\text { Tendency of women to have higher } \\
\text { betweenness }(\mathrm{H} 3) \text {. }\end{array}$ \\
\hline
\end{tabular}

The ALAAM estimates parameters relating various network (structural) and actor attributes to the log-odds for a binary outcome variable on each node, given a fixed network, and fixed attributes on the actors, but also taking account of the outcome variable on neighbouring nodes in the network. Here the outcome is gender (recoded as 1 for female, 0 for male), and the network is the collaboration network. The only other attribute used is the betweenness centrality of each actor (as previously described). In addition, a second network is used as a "setting", or environment in which the 
Table 3 Summary statistics for collaboration and pre-existing tie networks

\begin{tabular}{lllllllll}
\hline Network & $\mathrm{N}$ & Components & $\begin{array}{l}\text { Max. } \\
\text { component } \\
\text { size }\end{array}$ & $\begin{array}{l}\text { Mean density } \\
\text { degree }\end{array}$ & $\begin{array}{l}\text { Clustering } \\
\text { coefficient }\end{array}$ & $\begin{array}{l}\text { Assortativity } \\
\text { coefficient }\end{array}$ & $\begin{array}{l}\text { Mean } \\
\text { path } \\
\text { length }\end{array}$ \\
\hline $\begin{array}{l}\text { Collaboration } \\
\text { Pre-existing }\end{array}$ & 1390 & 115 & 709 & 3.14 & 0.00226 & 0.35973 & -0.00174 & 7.25 \\
\hline
\end{tabular}

relationships in the first network occur. Here this "setting" network is the pre-existing relationships network.

\section{Descriptive analysis results}

Table 3 shows summary statistics for the collaboration and pre-existing tie networks. Pre-existing ties form many components. The collaboration network has a maximum component of size 709, indicating that a considerable number of individuals in the dataset are connected by some path. Mean degree, network density and mean path length are higher in the collaboration network than in the network of pre-existing ties. The clustering coefficient indicates that there is more closure in the pre-existing tie network than in the collaboration network, which is unsurprising as networks of 'emotionally close' ties such as kinship or friendship tend to display closed structures [67]. The assortativity coefficient here is degree assortativity, or the tendency for vertices of similar degree to be connected. The assortativity coefficient is (strongly) positive for the pre-existing ties network, as is usual for social networks, but it is (slightly) negative for the collaboration network, which is unusual for social networks, which tend to be highly assortative [61]. This could be due to the data collection method - data is collated by a central agency from multiple investigations by different police forces. If these investigations are separate and focus on key persons of interest and their ties, there may be a lack of connectivity between high degree nodes in the data set. Alternatively, it could reflect the logic of criminal organization, in that important individuals tend to not connect directly with one another due to rivalry or to minimise risk [68]. Figure 1 shows the degree and component size distributions for the collaboration network.

Table 4 shows summary statistics of the two networks based on gender. Men have higher mean degree in the collaboration network than women. This provides

$\mathrm{N}=1390$, Median $=2$, Mean $=3.144$

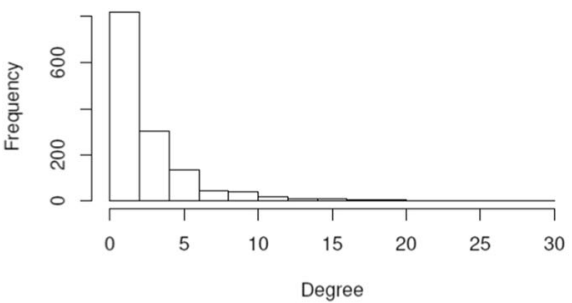

$\mathrm{N}=115$, Median $=3$, Mean $=12.09$

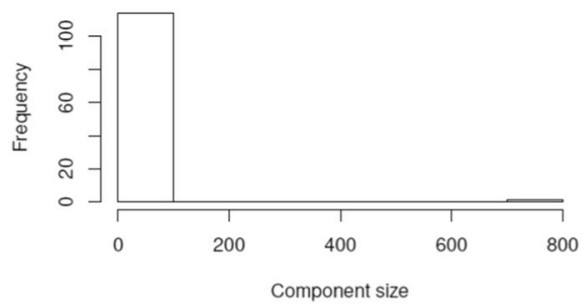

Fig. 1 Collaboration network degree and component size distributions 
Table 4 Summary statistics for collaboration and pre-existing tie networks based on gender

\begin{tabular}{lllllll}
\hline Network & \multicolumn{2}{l}{ Mean degree } & & & \multicolumn{2}{l}{ SD degree } \\
\cline { 2 - 3 } & Men & Women & & Men & Women & \\
\hline Collaboration & 3.27 & 2.35 & & 3.29 & 1.78 & 0.099 \\
Pre-existing & 0.287 & 0.303 & & 0.887 & 0.566 & 0.087 \\
\hline
\end{tabular}

support for hypothesis 2. The dispersion of degree in the collaboration network, as measured by its standard deviation, is also greater for men than for women. Women have higher mean degree in the pre-existing ties network, providing evidence for hypothesis 5. Women's degree dispersion is lower than men's in the pre-existing tie network. Table 2 also shows the assortativity coefficient for both networks. Here the assortativity coefficient is for assortativity on gender, or the tendency for nodes of the same gender to be connected (evidencing homophily). There is a very small positive gender assortativity in both networks, providing evidence against hypothesis 4 .

In order to investigate women's tendency to occupy central network positions relative to men, betweenness centrality was calculated for each node in the collaboration network using the igraph [69] package in $\mathrm{R}$ [70], without normalization. Table 5 shows summary statistics for betweenness centralities in the collaboration network. Men have higher mean betweenness centrality than women, and the nodes with the highest betweenness scores are men, indicating that men tend to be more powerful than women on this commonly-used measure of centrality. This provides support for hypothesis 3 .

Figures 2 and 3 are sociograms of the collaboration network and the pre-existing ties network. Figure 2 provides visual indication that nodes with high betweenness centrality tend to be male.

\section{Statistical modelling results}

Estimation of ALAAM parameters was done with IPNet [71]. The results are shown in Table 6 . The model is converged well with the convergence t-ratios for all parameters less than .1 in magnitude. Table 6 shows a small number of significant effects, with only three parameter estimates indicating statistically significant differences between the network positions of men and women. This suggests that the model did not detect any systematic differences between men and women in terms of their activity (captured

Table 5 Summary statistics of betweenness centrality of nodes in the collaboration network

\begin{tabular}{lllllll}
\hline Nodes & Min. & 1st Qu. & Median & Mean & 3rd Qu. & Max. \\
\hline All & 0.00 & 0.00 & 0.00 & 1163.82 & 59.25 & $75,085.64$ \\
Men & 0.00 & 0.00 & 0.00 & 1300.35 & 106.04 & $75,085.64$ \\
Women & 0.00 & 0.00 & 0.00 & 274.52 & 2.00 & 6132.62 \\
\hline
\end{tabular}




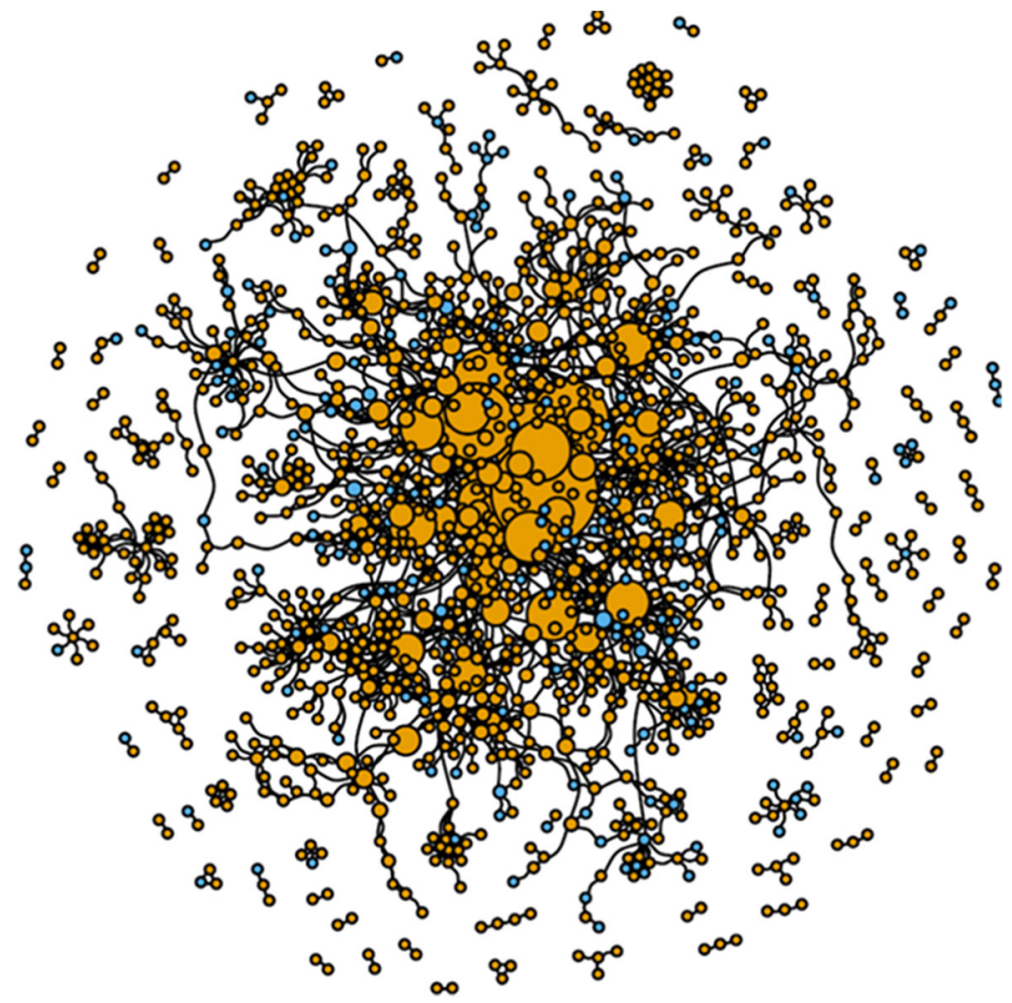

Fig. 2 Collaboration network visualized with the "graphopt" force-directed layout in igraph. The nodes are coloured according to gender (orange for men, blue for women) and sized proportionally to their betweenness centrality

by the effects of activity, star2, and star3 effects), involvement in closed structures (captured by T1, T2, and T3 effects), involvement via partners (partner-activity and partner-resource effects) and involvement via pre-existing ties (setting-homophily effect). Also, despite the descriptive statistics indicating that men have higher mean betweenness centrality than women, the effect of node's betweenness centrality is nonsignificant when we account for the other structural effects in the model. Therefore, we find no support for hypotheses 2, 3, 5, and 7 conditional on the other significant effects.

There are three significant effects in the model. The first one is the attribute-density, which controls for the smaller number of women in the network than men. This supports hypothesis 1 and indicates that at least in terms of men to women ratio in organized crime, the gender gap has not been closed. Another significant effect is contagion, denoting homophily. Here, we see a positive sign suggesting the tendency of women to be associated with other women in the network rather than with men. This contradicts hypothesis 4 , which predicts heterophilous tendencies for women. The finding that women in organized crime have homophilous tendencies is contrary to some previous findings [46, 72], although these analyses did not specifically control for the proportion of women in the network as well as brokerage tendencies. The last significant effect is the two-path-equivalence. This effect is related to brokerage 


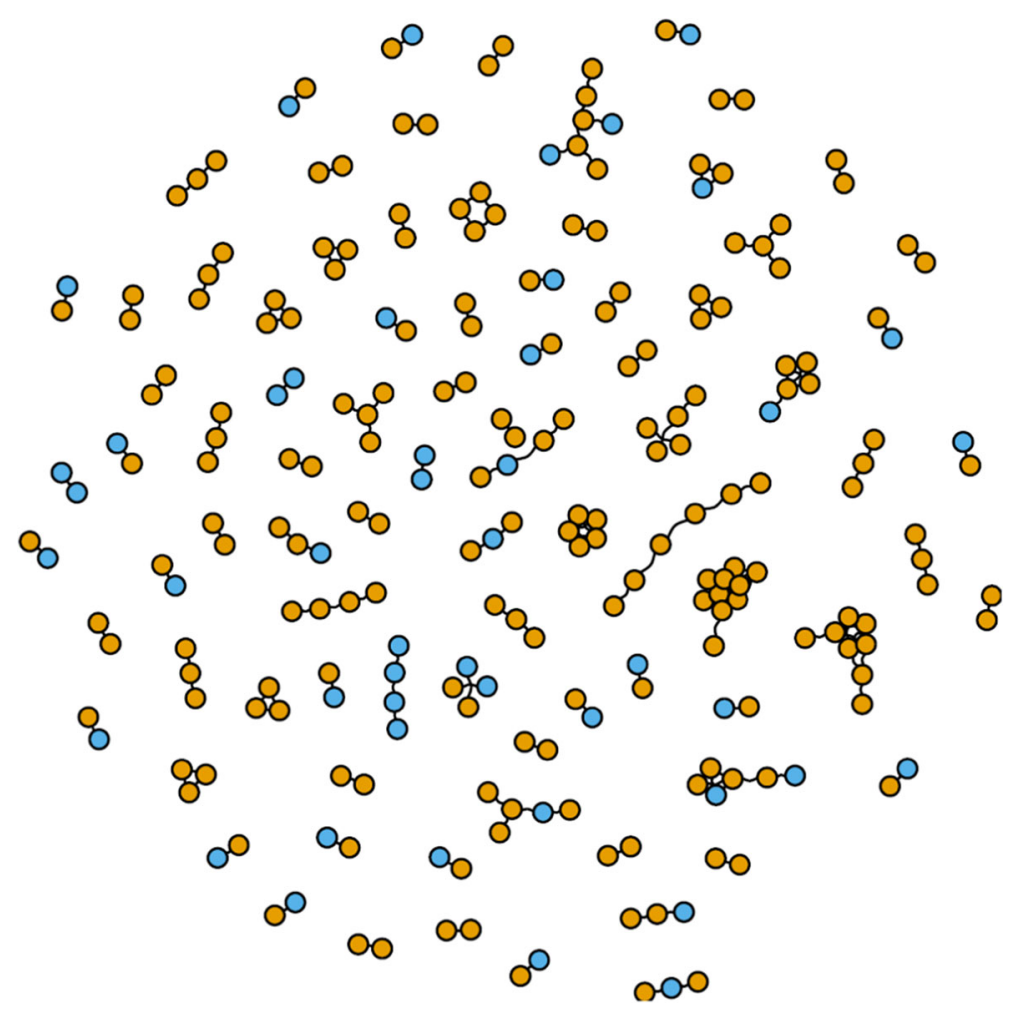

Fig. 3 Pre-existing ties network, with isolates removed, visualized with the "graphopt" force-directed layout in igraph. The nodes are coloured according to gender (orange for men, blue for women)

positions and is interpreted as indicating structural equivalence between women, i.e. women tend to occupy structurally equivalent positions in the collaboration network. Given the other two-path configurations in the model this effect captures the situation in which a male actor brokers between two women who don't have a direct connection to one another, potentially giving the male broker an advantage over his female associates. This effect is positive, suggesting that women are more likely to be in structurally equivalent and disadvantageous positions of being brokered between by men. Again, this finding is at odds with some previous research which found women occupying brokerage positions [36, 57]. This result is more consistent with women being introduced into the network by men, than replacing men who have died or been imprisoned.

Table 7 shows the goodness of fit statistics for the model. ${ }^{3}$ The t-ratios of each parameter included in the model are all smaller than 0.3 in magnitude, suggesting acceptable fit of the model to the data.

\footnotetext{
${ }^{3}$ Goodness of fit is assessed by simulating networks statistics from the estimated model, and calculating tratios based on comparison of the observed network statistics to the distribution of simulated network statistics. A rule of thumb for adequate fit is t-ratios less than 0.3 for statistics included in the model [63].
} 
Table 6 Results of ALAAM for the collaboration network

\begin{tabular}{|c|c|c|c|}
\hline Effect & Parameter & Std. Error & \\
\hline Attribute-Density & -1.668994 & 0.25009 & $*$ \\
\hline Activity & -0.214388 & 0.16833 & \\
\hline Star2 & 0.000161 & 0.08076 & \\
\hline Star3 & 0.002306 & 0.01249 & \\
\hline Contagion & 1.159325 & 0.28113 & $*$ \\
\hline $\mathrm{T} 1$ & 0.004614 & 0.04561 & \\
\hline $\mathrm{T} 2$ & 0.196052 & 0.24778 & \\
\hline $\mathrm{T} 3$ & -1.015396 & 1.11464 & \\
\hline Setting-Homophily & 0.07685 & 0.21338 & \\
\hline 2-Path-Equivalence & 0.100845 & 0.0206 & $*$ \\
\hline Partner-Activity & -0.153155 & 0.09838 & \\
\hline Partner-Resource & 0.092529 & 0.13832 & \\
\hline Betweenness Centrality & -0.000087 & 0.00008 & \\
\hline
\end{tabular}

\section{Discussion}

The results of our analysis are surprising in the sense that where previous research on the role of gender in criminal contexts suggests that there ought to be numerous structural differences between men's and women's networks, we found relatively few significant differences between the structural positions of men and women in our observed network. A number of differences between men and women's networks suggested by the descriptive statistics were contradicted or clarified by the modelling results (ALAAM). While descriptive analysis shows that women on average have

Table 7 Goodness of fit statistics of the ALAAM for the collaboration network

\begin{tabular}{lcccc}
\hline Configuration & Observed & Simulated Mean & Simulated SD & t-ratio \\
\hline Attribute-Density & 185 & 184.0230 & 16.7766 & 0.0582 \\
Activity & 435 & 427.8310 & 51.9741 & 0.1379 \\
Star2 & 586 & 561.7940 & 129.6385 & 0.1867 \\
Star3 & 844 & 783.6890 & 439.5816 & 0.1372 \\
Contagion & 41 & 39.7710 & 10.6209 & 0.1157 \\
T1 & 341 & 324.3010 & 86.3678 & 0.1933 \\
T2 & 62 & 55.9350 & 27.8699 & 0.2176 \\
T3 & 5 & 4.3190 & 3.6944 & 0.1843 \\
Setting-Homophily & 6 & 5.2250 & 4.7918 & 0.1617 \\
2-Path-Equivalence & 224 & 202.2290 & 87.5454 & 0.2487 \\
Partner-Activity & 205 & 190.0850 & 73.3764 & 0.2033 \\
Partner-Resource & 52 & 46.0400 & 30.385 & 0.1961 \\
Betweenness Centrality & $50,785.743$ & $50,710.7638$ & $17,338.0992$ & 0.0043 \\
\hline
\end{tabular}


lower betweenness centrality in the collaboration network than men, the results of the ALAAM indicate no significant tendency towards lower betweenness centrality for women. Further, while the descriptive statistics show weak support for gender homophily, the modelling results indicate a significant positive tendency towards homophily in the collaboration network. Finally, while women have more preexisting ties on average than men, modelling results indicate that women do not tend to have a greater tendency to collaborate with one another via pre-existing ties than men do. These results demonstrate the importance of comparing men and women's criminal network positions using methods such as ALAAM that account systematically for network tie dependencies, and that acknowledge the fact that lower-order network configurations are nested within higher-order configurations. Thus the interpretations of particular structural features of a network may be explained or strengthened when we account for lower-order and other theoretically-relevant configurations.

However, our modelling results indicate that women are overall less likely to participate in the network, when they participate they associate significantly more frequently with other women, and they tend to be on the potentially less advantageous ends of open brokerage structures. These results provide evidence for an ongoing gender gap in organized crime. Research in legitimate contexts has found evidence for a 'structural perspective', where gender differences in networks are explained by opportunities and constraints in network formation presented by men and women's differential positions in the broader economic and societal structure [9, 10, 31]. On this view, the observation that women are both less present and less active in the network of organized criminals connected to the Canadian province of Alberta may reflective of a systemic lack of opportunities for women to participate in organized crime, or systemic constraints preventing women from joining the network. For example, women may lack opportunities to form network ties because they are excluded from convergence settings such as dive bars where criminal collaborations arise and crimes are planned [11] and so they are unable to learn about criminal opportunities or become involved in criminal conspiracies [10]. Constraints may include a relative lack of the resources required to be of use to criminal organizations, or a cultural perception among criminals that women should not or cannot participate in criminal activities [9]. Furthermore, gender stereotypes operating in wider society may affect the positions of women in criminal networks. Societal expectations and gender relations are geared towards men holding positions of influence and power $[19,20]$, and as such men may work to keep women excluded from powerful positions within criminal networks. For instance, some research suggests that male criminals' perceptions that women are untrustworthy, unreliable, or weak is a barrier to women's entry into, and acquisition of advantageous positions within, organized crime $[6,7]$.

Our finding that when women do participate they tend to occupy the potentially disadvantageous ends of open brokerage structures, with men occupying the broker position, suggests that women may be 'used' by men for what resources they have, without exercising true power in the form of the coordination or orchestration of criminal activities. While in other contexts brokerage behaviour has been viewed mainly as a source of performance advantages for individuals and groups [53, 54], in criminal networks it has also been seen as a source of covertness [56] or as a niche role in the organization of criminal activity [57]. Combining these functions of brokerage, occupying brokerage positions may be a source of potential power in criminal 
collaboration networks in that it could allow individuals to control information and resources while maintaining concealment and allowing the accumulation of advantage. Thus the fact that women tend to be brokered between by men in our data evidences their systematic lack of power in comparison to men. The observation that women tend to 'flock together' [43] also implies that when women do participate in organized crime it may be in niche activities or segments of the criminal supply chain [26] that are open to women, such as sex or human trafficking. Taken together, these findings provide evidence that women tend to participate in organized crime either in peripheral, lowpower positions or in groups with other women, in accordance with some previous findings (cf. $[9,10])$.

Finally, the finding that there is no tendency towards heterophily in women's network ties, alongside women's minority position in the network in terms of overall numbers, might speak to a lack of opportunities by which women are able to form ties with and access resources from important men in the network. In contrast, research on legitimate organizations has found that women tend to violate homophily preferences in order to access resources from powerful actors, and this may be a mechanism by which women who are in a minority position increase their power [73].

In sum, while our findings do not accord fully with previous research regarding differences in the structural positions of men and women in criminal networks, they do provide evidence for an ongoing gender gap in involvement in organized crime. In other words, it appears that organized crime continues to be predominantly 'a man's world'.

\section{Conclusions and future research directions}

We formulated our hypotheses and specified our model based on previous research on the positions of men and women in organized crime and on the differences in positions between men and women in legitimate networks. Most of the former studies are qualitative case studies on different criminal groups focusing specifically on what women do within these groups. This provides great detail and the contextual information on women's roles in organised crime and how women acquire certain positions. This depth is, however, perhaps achieved at the expense of systematic comparison between men and women. The social network perspective and specific models such as ALAAM offer a way to make such a comparison. Statistical models for social networks allow us to show that in our specific case, we do not find evidence for the differences in the structural positions of women compared with men in organized crime, as apparent structural differences may be due to structural social processes that are not genderspecific and are not accounted for by simple descriptive network analysis. However, further research is necessary in order to say whether our findings differ from previous research because of the use of our statistical models or because our case itself is different from other cases. The present study provides an insight into differences between men and women in organized crime in one large network, albeit in a particular societal, geographic and temporal context. In order to gain a more solid picture of the gender differences in organized crime, it is necessary to study other criminal networks and accumulate findings on consistently appearing patterns concerning gender therein, which provide systematic evidence of the roles women play in organised crime. 
One avenue for further research would be the investigation of how the activities of criminal groups affect the involvement and structural positions of women within the groups. There may be differential rates of involvement in different types of organized criminal activities or groups [6]. We might expect that women are less involved in those types of organized crime which require more "professional" involvement, and where stakes and risks are higher (Steffensmeier and Allan [2]) (although there are counterexamples in the trafficking industry). Some researchers hypothesize that women are less likely to be involved in violent activities, a hypothesis sometimes referred to as the gendered market hypothesis $[36,46]$. Connell's $[19,20]$ social theory of gender argues that violence is a means by which men maintain power over women - violence is regarded as 'natural' for men, but not for women - so there are ways that broader social theory may be informative here as well. Answering these questions will likely prove valuable in understanding organized crime.

Another avenue for future research is the dynamics of criminal networks. Our study provides a static picture of positions of men and women in one criminal network, but in order to better understand the differences between genders it is important to consider the evolution of these differences over time. In other words, an important issue is whether the crime gender gap is narrowing or widening over time and in what aspects in the sheer involvement of women, in their structural positions or in both? A longitudinal perspective would also allow us to better understand the mechanisms behind the formation of criminal networks. For example, given that we observe that women tend to be brokered between by men, we may wonder if there is a high rate of 'churn' of women occupying this structural position in the network. If so this would suggest that women play a relatively dispensable role in criminal networks, where they are used for their resources and then discarded. There has been vigorous development of longitudinal models for networks in SNA [74] which are capable of separating the influence of endogenous network effects, attribute effects, and exogenous dyadic effects on the evolution of the network as well as attributes over time. Thus far these models have been relatively little-used in criminal network research. Combining longitudinal network data with qualitative or ethnographic data about broader social, economic, and political context would also be a fruitful avenue in studying how changes at the societal level translate into individual positions of men and women in the structures of organized crime.

The study of both the different activities within criminal networks and network dynamics require suitable data. As we have noted above, collection of complete and reliable data is probably the largest challenge in the study of criminal networks [26, 27] and it also presents the greatest limitation of our present study. It is impossible to know whether the observed differences between men and women in our network are a true reflection of the phenomenon of organized crime, or whether they are an artefact of data collection, recording and collation methods. For example, women may appear less present in the observed network because law enforcement tend to focus attention on male criminals while paying less attention to the kinds of crime that women are involved in. In addition, we found no evidence that women are more likely to be connected by pre-existing ties in the network. However, the way in which our data was collected and collated means that the number of pre-existing ties may be underestimated and their temporal precedence to collaboration ties is uncertain. Time-stamped data, indicating the precise temporal order of tie formation, would 
provide further evidence on interrelationships among types of ties in criminal networks. However, as more and more studies reveal interesting and valuable insights, law enforcement practitioners collect more valuable data and are increasingly interested in the field of criminal network analysis. Researchers may take advantage of this momentum and propagate good practices for collecting and processing data on covert populations to further advance the area of inquiry.

Open Access This article is licensed under a Creative Commons Attribution 4.0 International License, which permits use, sharing, adaptation, distribution and reproduction in any medium or format, as long as you give appropriate credit to the original author(s) and the source, provide a link to the Creative Commons licence, and indicate if changes were made. The images or other third party material in this article are included in the article's Creative Commons licence, unless indicated otherwise in a credit line to the material. If material is not included in the article's Creative Commons licence and your intended use is not permitted by statutory regulation or exceeds the permitted use, you will need to obtain permission directly from the copyright holder. To view a copy of this licence, visit http://creativecommons.org/licenses/by/4.0/.

\section{References}

1. Kruttschnitt, C. (2013). Gender and crime. Annual Review of Sociology, 39(1), 291-308. https://doi. org/10.1146/annurev-soc-071312-145605.

2. Steffensmeier, D., \& Allan, E. (1996). Gender and crime: Toward a gendered theory of female offending. Annual Review of Sociology, 22(1), 459-487. https://doi.org/10.1146/annurev.soc.22.1.459.

3. Tracy, P. E., Kempf-Leonard, K., \& Abramoske-James, S. (2009). Gender differences in delinquency and juvenile justice processing: Evidence from National Data. Crime \& Delinquency, 55(2), 171-215. https://doi.org/10.1177/0011128708330628.

4. Siegel, L. (2014). Criminology: The Core (5th ed.). Stamford, CT, USA: Wadsworth Publishing.

5. Arsovska, J., \& Allum, F. (2014). Introduction: Women and transnational organized crime. Trends in Organized Crime, 17(1-2), 1-15. https://doi.org/10.1007/s12117-014-9223-y.

6. Beare, Margaret. 2010. 'Women and organized crime'. Research and National Coordination Organized Crime Division Law Enforcement and Policy Branch Public Safety Canada.

7. Smith, Chris. 2015. The Shifting Structure of Chicago's Organized Crime Network and the Women It Left Behind. Doctoral dissertations may 2014 - current. 453.

8. Bunt, Henk van de, Dina Siegel, and Damián Zaitch. 2014. 'The social Embeddedness of organized crime'. In The Oxford Handbook of Organized Crime, edited by Letizia Paoli, 1 edition, 321-39. Oxford: Oxford University Press.

9. Schwartz, J., \& Steffensmeier, D. (2017). Gendered opportunities and risk Preferencesfor offending across the life course. Journal of Developmental and Life-Course Criminology, 3(2), 126-150. https://doi.org/10.1007/s40865-016-0050-5.

10. Steffensmeier, D. J., Schwartz, J., \& Roche, M. (2013). Gender and twenty-first-century corporate crime: Female involvement and the gender gap in Enron-era corporate frauds. American Sociological Review, 78(3), 448-476. https://doi.org/10.1177/0003122413484150.

11. Felson, Marcus. 2006. 'The ecosystem for organized crime'. 26. Helsinki.

12. Paoli, L. (Ed.). (2014). The Oxford handbook of organized crime (1st ed.). Oxford: Oxford University Press.

13. Emerson, R. M. (1976). Social exchange theory. Annual Review of Sociology, 2, 335-362.

14. Borgatti, S. P., Everett, M. G., \& Johnson, J. C. (2013). Analyzing social networks. London: Sage.

15. Prell, Christina. 2011. Social Network Analysis. 1 edition. Los Angeles ; London: SAGE Publications Ltd.

16. Scott, John, and Peter J. Carrington. 2011. The SAGE handbook of social network analysis. SAGE.

17. Carrington, P.J. 2011. 'Crime and social network analysis'. In The SAGE Handbook of Social Network Analysis, 2011:236-55.

18. McIlwain, J. S. (1999). Organized crime: A social network approach. Crime, Law \& Social Change, 32, 301-323. 
19. Connell, R. (1987). Gender and power: Society, the person, and sexual politics. Stanford, Calif: Stanford University Press.

20. Connell, R. (2005). Masculinities. Berkeley, Calif: University of California Press.

21. Daraganova, Galina, and Garry Robins. 2013. 'Autologistic actor attribute models'. In Exponential Random Graph Models for Social Networks: Theory, Methods, and Applications, edited by dean Lusher, Johan Koskinen, and Garry Robins, 102-14. Structural analysis in the social sciences 32. Cambridge: Cambridge University press.

22. Robins, G., Pattison, P., \& Elliott, P. (2001). Network models for social influence processes. Psychometrika, 66(2), 161-189. https://doi.org/10.1007/BF02294834.

23. Le, V. (2012). Organized crime typologies: Structure, activities and conditions. International Journal of Criminology and Sociology, 1(0), 121-131.

24. Campana, P. (2016). Explaining criminal networks: Strategies and potential pitfalls. Methodological Innovations, 9(January), 2059799115622748. https://doi.org/10.1177/2059799115622748.

25. Cunningham, Daniel, Sean Everton, and Philip Murphy. 2016. Understanding dark networks: A strategic framework for the use of social network analysis. Reprint ed. Lanham: Rowman \& Littlefield Publishers.

26. Morselli, C. (2009). Inside criminal networks. New York: Springer International Publishing.

27. Morselli, C. (2014). Crime and networks. New York: Routledge.

28. Bright, D. A., Greenhill, C., Reynolds, M., Ritter, A., \& Morselli, C. (2015). The use of actor-level attributes and centrality measures to identify key actors: A case study of an Australian drug trafficking network. Journal of Contemporary Criminal Justice, 31(3), 262-278. https://doi.org/10.1177 /1043986214553378.

29. Calderoni, F. (2012). The structure of drug trafficking mafias: The Ndrangheta and cocaine. Crime, Law \& Social Change, 58(3), 321-349. https://doi.org/10.1007/s10611-012-9387-9.

30. Robins, G. (2009). Understanding individual behaviors within covert networks: The interplay of individual qualities, psychological predispositions, and network effects. Trends in Organized Crime, 12(2), 166-187. https://doi.org/10.1007/s12117-008-9059-4.

31. Moore, G. (1990). Structural determinants of Men's and Women's personal networks. American Sociological Review, 55(5), 726. https://doi.org/10.2307/2095868.

32. Lutter, M. (2015). Do women suffer from network closure? The moderating effect of social capital on gender inequality in a project-based labor market, 1929 to 2010. American Sociological Review, 80(2), 329-358. https://doi.org/10.1177/0003122414568788.

33. McDonald, S. (2011). What's in the "old boys" network? Accessing social Capital in Gendered and Racialized Networks. Social Networks, 33(4), 317-330. https://doi.org/10.1016/j.socnet.2011.10.002.

34. Piselli, F. (2009). Network analysis in the study of gender differences. International Review of Sociology, 19(1), 147-154. https://doi.org/10.1080/03906700802614093.

35. Pizzini-Gambetta, Valeria. 2014. 'Organized crime: The gender constraints of illegal markets'. In The Oxford Handbook of Gender, Sex, and Crime, edited by rosemary Gartner and bill McCarthy. Oxford: Oxford University Press.

36. Kleemans, E. R., Kruisbergen, E. W., \& Kouwenberg, R. F. (2014). Women, brokerage and transnational organized crime. Empirical results from the Dutch organized crime monitor. Trends in Organized Crime, 17(1-2), 16-30.

37. Campedelli, G. M., Calderoni, F., Comunale, T., \& Meneghini, C. (2019). Life-course criminal trajectories of mafia members. Crime \& Delinquency., 001112871986083. https://doi.org/10.1177 /0011128719860834.

38. Fuller, Georgina, Anthony Morgan, and Rick Brown. 2019. "Criminal histories of Australian organised crime offenders." 567. Trends \& Issues in crime and criminal Justice. Canberra: Australian Institute of Criminology.

39. Oliver, K., Crossley, N., Everett, M. G., Edwards, G., \& Koskinen, J. (2014). Covert networks: Structures, processes and types. The Mitchell Center for Social Network Analysis working paper. http://www. socialsciences.manchester.ac.uk/medialibrary/research/mitchell/covertnetworks/wp/working_paper1.pdf

40. Willer, D. (1992). Predicting power in exchange networks: A brief history and introduction to the issues. Social Networks, 14(3-4), 187-211. https://doi.org/10.1016/0378-8733(92)90001-N.

41. Freeman, L. C. (1978). Centrality in social networks conceptual clarification. Social Networks, 1(3), 215239. https://doi.org/10.1016/0378-8733(78)90021-7.

42. Edling, C., Farkas, G., \& Rydgren, J. (2013). Women in power: Sex differences in Swedish local elite networks. Acta Sociologica, 56(1), 21-40. https://doi.org/10.1177/0001699312468803.

43. McPherson, M., Smith-Lovin, L., \& Cook, J. M. (2001). Birds of a feather: Homophily in social networks. Annual Review of Sociology, 27(2001), 415-444. https://doi.org/10.1146/annurev. soc.27.1.415. 
44. Rivera, M. T., Soderstrom, S. B., \& Uzzi, B. (2010). Dynamics of dyads in social networks: Assortative, relational, and proximity mechanisms. Annual Review of Sociology, 36(1), 91-115. https://doi. org/10.1146/annurev.soc.34.040507.134743.

45. Allum, F. (2007). Doing it for themselves or standing in for their men? Women in the Neapolitan camorra (1950-2003). In G. Fiandaca (Ed.), Women and the mafia. Springer.

46. Zhang, S. X., Chin, K.-L., \& Miller, J. (2007). Women's participation in Chinese transnational human smuggling: A gendered market perspective. Criminology, 45(3), 699-733. https://doi.org/10.1111 /j.1745-9125.2007.00085.x.

47. Burt, R. S. (1998). The gender of social capital. Rationality and Society, 10(1), 5-46. https://doi. org/10.1177/104346398010001001.

48. von Mastrigt, S. B., \& Carrington, P. J. (2014). Sex and age Homophily in co-offending networks: Opportunity or preference? In C. Morselli (Ed.), Crime and networks (pp. 28-51). New York: Routledge.

49. Diviák, T., Dijkstra, J. K., \& Snijders, T. A. B. (2018). Structure, Multiplexity, and centrality in a corruption network: The Czech Rath affair. Trends in Organized Crime, March., 22, 274-297. https://doi.org/10.1007/s12117-018-9334-y.

50. Campana, P., \& Varese, F. (2013). Cooperation in criminal organizations: Kinship and violence as credible commitments. Rationality and Society, 25(3), 263-289. https://doi.org/10.1177 /1043463113481202.

51. von Lampe, K., \& Johansen, P. O. (2004). Organized crime and trust: On the conceptualization and empirical relevance of Trust in the Context of criminal networks. Global Crime, 6(2), 159-184. https://doi.org/10.1080/17440570500096734.

52. Di Maria, F., \& Lo Verso, G. (2007). Women in mafia organizations. In G. Fiandaca (Ed.), Women and the mafia. Springer.

53. Burt, R. S. (1992). Structural holes: The social structure of competition. Cambridge MA: Harvard University Press.

54. Burt, R. S. 2005. Brokerage and closure: An introduction to social capital. Oxford University Press.

55. Morselli, C., \& Roy, J. (2008). Brokerage qualifications in ringing operations. Criminology, 46(1), 7198. https://doi.org/10.1111/j.1745-9125.2008.00103.x.

56. Morselli, C. (2010). Assessing vulnerable and strategic positions in a criminal network. Journal of Contemporary Criminal Justice, 26(4), 382-392. https://doi.org/10.1177/1043986210377105.

57. Mancuso, M. (2014). Not all madams have a central role: Analysis of a Nigerian sex trafficking network. Trends in Organized Crime, 17(1/2), 66-88. https://doi.org/10.1007/s12117-013-9199-z.

58. Coleman, J. S. (1988). Social Capital in the Creation of human capital. American Journal of Sociology, 94, S95-S120.

59. Canadian Centre on Substance Use and Addiction. 2018. 'Drug Summary: Methamphetamine'. http://www.ccsa.ca/Resource\%20Library/CCSA-Canadian-Drug-Summary-Methamphetamine-2018-en. pdf.

60. Rostami, A., and Mondani, H. 2015. 'The complexity of crime network data: A case study of its consequences for crime control and the study of networks'. Edited by Thomas Niederkrotenthaler. PLOS ONE 10 (3): e0119309. https://doi.org/10.1371/journal.pone.0119309.

61. Newman, M. E. J., \& Park, J. (2003). Why social networks are different from other types of networks. Physical Review E, 68(3). https://doi.org/10.1103/PhysRevE.68.036122.

62. Newman, M. E. J. (2003). Mixing patterns in networks. Physical Review E, 67(2). https://doi.org/10.1103 /PhysRevE.67.026126.

63. Robins, G. (2013). A tutorial on methods for the modeling and analysis of social network data. Journal of Mathematical Psychology, Social Networks, 57(6), 261-274. https://doi.org/10.1016/j.jmp.2013.02.001.

64. Snijders, T. A. B. (2011). Statistical models for social networks. Annual Review of Sociology, 37(1), 131153. https://doi.org/10.1146/annurev.soc.012809.102709.

65. Cai, W., Guan, G., Pan, R., Zhu, X., \& Wang, H. (2018). Network linear discriminant analysis. Computational Statistics \& Data Analysis, 117(January), 32-44. https://doi.org/10.1016/j. csda.2017.07.007.

66. Kashima, Y., Wilson, S., Lusher, D., Pearson, L. J., \& Pearson, C. (2013). The Acquisition of Perceived Descriptive Norms as social category learning in social networks. Social Networks, 35(4), 711-719. https://doi.org/10.1016/j.socnet.2013.06.002.

67. Granovetter, M. (1973). The strength of weak ties. American Journal of Sociology, 78(6), 1360-1380. https://doi.org/10.1086/225469.

68. Wood, G. (2017). The structure and vulnerability of a drug trafficking collaboration network. Social Networks, 48, 1-9. https://doi.org/10.1016/j.socnet.2016.07.001. 
69. Csardi, Gabor, and Tamas Nepusz. 2006. The Igraph Software Package for Complex Network Research. http://igraph.sf.net.

70. R Core Team. 2018. R: A language and environment for statistical computing. Vienna, Austria: R Foundation for Statistical Computing. https://www.R-project.org/.

71. Wang, Peng, Garry Robins, and Pip Pattison. 2009. PNet: Program for the simulation and estimation of exponential random graph $\left(\mathrm{P}^{*}\right)$ models. University of Melbourne.

72. Fiandaca, G. (Ed.). (2007). Women and the mafia. New York, NY: Springer.

73. Ibarra, H. (1992). Homophily and differential returns: Sex differences in network structure and access in an advertising firm. Administrative Science Quarterly., 37, 422. https://doi.org/10.2307/2393451.

74. Snijders, T. A. B., van de Bunt, G. G., \& Steglich, C. E. G. (2010). Introduction to stochastic actor-based models for network dynamics. Social Networks, 32(1), 44-60. https://doi.org/10.1016/j. socnet.2009.02.004.

Publisher's note Springer Nature remains neutral with regard to jurisdictional claims in published maps and institutional affiliations.

\section{Affiliations}

\section{Tomáš Diviák ${ }^{1,2,3}$ • James A. Coutinho ${ }^{4}$ Alex D. Stivala ${ }^{4,5}$}

1 Department of Sociology, University of Groningen/ICS, Grote Kruisstraat 2/1, 9712 TSGroningen, The Netherlands

2 Charles University, Prague, Czechia

3 University of Manchester, Manchester, England

4 Swinburne Business School, Swinburne University of Technology, Melbourne, Australia

5 Università della Svizzera italiana, Lugano, Switzerland 